\title{
ANÁLISE RELACIONAL ENTRE O DESEMPENHO AMBIENTAL, SOCIAL E \\ ECONÔMICO: ESTUDO DAS CORPORAÇÕES COM SELO ISE DA BM\&FBOVESPA
}

\author{
André Luis Gabriel ${ }^{1}$ \\ Alexandre André Feil ${ }^{2}$ \\ Recebido em: 08 mar. 2018 \\ Aceito em: 18 fev. 2019
}

\begin{abstract}
Como citar este artigo: GABRIEL, André Luis; FEIL, Alexandre André. ANÁLISE RELACIONAL ENTRE O DESEMPENHO AMBIENTAL, SOCIAL E ECONÔMICO: ESTUDO DAS CORPORAÇÕES COM SELO ISE DA BM\&FBOVESPA. Revista Visão: Gestão Organizacional, Caçador, SC, Brasil, p. 07-24, jun. 2019. ISSN 2238-9636. Disponível em:

<http://dx.doi.org/10.33362/visao.v8i1.1410>.
\end{abstract}

Resumo: Este estudo objetiva analisar a relação entre os investimentos ambientais, sociais e econômicos das corporações cadastradas no Índice de Sustentabilidade Empresarial (ISE) da BM\&FBovespa de 2016. A metodologia é quantitativa, descritiva e o procedimento técnico é a pesquisa documental. A análise dos dados ocorreu mediante testes estatísticos, sendo a correlação de Pearson, Teste $t$ de student, Teste de Levene e pelo coeficiente de variação. Os resultados apontam que o desempenho ambiental mais eficiente é das corporações dos setores de combustível, alimentício e de extração de recursos naturais; ao analisar a dimensão social, destacam-se os setores de transportes e de energia elétrica; e, na dimensão econômica, destacam-se as organizações dos serviços financeiros. A análise de variância com base no Teste Levene $F(1,296)=0,263$ e $t$ de Student $(0,246)=0,807$ revelam um $p>0,05$, neste sentido, sugerem que não há diferença entre a média do desempenho ambiental e social. Além disso, o teste Pearson revela que não há correlações significativas do desempenho ambiental e social em relação ao desempenho econômico. Conclui-se que a geração de lucro ou prejuízo das corporações da carteira ISE da BM\&FBovespa de 2016 não influencia no montante de investimento realizado no âmbito ambiental e social.

Palavras-Chave: Índice de Sustentabilidade Empresarial. Correlação de Pearson. Teste $t$ de Student.

RELATIONAL ANALYSIS BETWEEN ENVIRONMENTAL, SOCIAL AND ECONOMIC PERFORMANCE: STUDY OF CORPORATIONS WITH ISE OF BM\& FBOVESPA

Abstract: This study aims to analyze the relationship between environmental, social and

\footnotetext{
1 André Luis Gabriel, Bacharel em Ciências contábeis, Universidade do Vale do Taquari - UNIVATES, andreluisgabriel@yahoo.com.br.

2 Alexandre André Feil, Doutor em Qualidade Ambiental pela Universidade Feevale, Docente adjunto do curso de ciências contábeis, Docente permanente do Mestrado em Sistemas Ambientais Sustentáveis da Universidade do Vale do Taquari-UNIVATES, afeil@univates.br.
} 
economic investments of corporations registered in the BM\&FBovespa Corporate Sustainability Index (CSI) of 2016. The methodology is quantitative, descriptive and the technical procedure is documentary research. Data analysis was performed using statistical tests, Pearson correlation, Student t test, Levene test and coefficient of variation. The results indicate that the most efficient environmental performance is of the corporations of the fuel, food and natural resources extraction sectors; when analyzing the social dimension, the sectors of transport and electric energy stand out; and, in the economic dimension, the financial services organizations stand out. The analysis of variance based on the Levene $F$ test $(1.296)=0.263$ and Student $t(0.246)=$ 0.807 revealed a $p>0.05$, in this sense, suggest that there is no difference between the average environmental and social performance. In addition, the Pearson test reveals that there are no significant correlations of environmental and social performance in relation to economic performance. It's concluded that the generation of profit or loss of the corporations of the BM\&FBovespa CSI portfolio of 2016 does not influence the amount of investment made in the environmental and social scope.

Keywords: Corporate Sustainability Index. Pearson correlation. Test $t$ of Student.

\section{INTRODUÇÃO}

O desenvolvimento econômico teve início com a Revolução Industrial, no século XVIII, e atrelado a este desenvolvimento ocorreu a exploração dos recursos ambientais e consequentemente gerou impactos negativos ao meio ambiente (SOUZA; RÁSIA, JACQUES, 2010). Este desenvolvimento econômico pós Revolução Industrial refletiu um aumento do consumo dos recursos naturais extraídos do meio ambiente pelas indústrias, como sendo recursos originados do meio ambiente, sem custos e sem preocupar-se com a sua abundância, as empresas exploravam elevadas quantidades, que ocasionaram impactos ambientais negativos no mesmo âmbito (RIBEIRO; MARTINS, 1993).

A Conferência das Nações Unidas sobre o Meio Ambiente Humano, também denominada de Conferência de Estocolmo, realizada em 1972, inaugurou as tratativas na busca pelo equilíbrio entre o desempenho econômico e da degradação ambiental (UNITED NATIONS, 1972). Esta ideia gerou a noção de desenvolvimento sustentável em 1987 no relatório de Brundtland que trouxe a ideia da responsabilidade social, adequações ambientais e o desenvolvimento econômico. Neste sentido, a busca pela mitigação dos impactos negativos ao meio ambiente gerou estratégias organizacionais por meio de ações de responsabilidade social, consumo consciente dos recursos naturais, produtos verdes, sustentabilidade empresarial, entre outros.

As corporações comprometidas com a responsabilidade social e ambiental podem conceber maior lucratividade e um crescimento decorrente do tratamento aos seus empregados, clientes, investidores (ORLITZKY; SCHMIDT; RYNES, 2003). O acompanhamento da lucratividade pode ser realizado pelo desempenho empresarial, ou seja, por meio do 
desempenho econômico, social e ambiental. A avaliação de desempenho empresarial é considerado imprescindível na avaliação da direção e da identificação de pontos fortes e frágeis das organizações (WERNKE; LEMBECK, 2004).

A ideia da influência do desempenho ambiental e social da corporação no desempenho econômico apresenta resultados conflitantes (SOANA, 2011). Com base nesta constatação pode-se destacar que estudos precedentes sobre a existência desta influência foram realizados por Alves et al. (2013) que sugerem que existe correlação entre desempenho ambiental e o econômico, já Roldan et al. (2012) não apontam correlações significativas. Orlitzky, Schmidt e Rynes (2003) sugerem que a relação entre os desempenhos social, ambiental e econômico é multifacetada.

Neste contexto, este estudo objetiva analisar a relação entre os investimentos ambientais, sociais e econômicos de corporações da carteira ISE da BM\&FBovespa de 2016. Os resultados deste estudo podem contribuir com a discussão relacionada a influência do desempenho ambiental e social no econômico, o que torna a discussão na literatura com maior consistência.

\section{REFERENCIAL TEÓRICO}

\section{DESENVOLVIMENTO SUSTENTÁVEL E A GESTÃO AMBIENTAL}

O desenvolvimento sustentável é definido como "[...] aquele que atende às necessidades do presente sem comprometer a possibilidade de as gerações futuras atenderem às suas próprias necessidades" (WCED, 1987, p. 19). Este desenvolvimento é um sistema sustentável que pode efetivamente manter-se e auto abastecer-se ao longo de sua existência, em outras palavras, um sistema sustentável gera, ele próprio, os insumos necessários à sua manutenção (YAMAGUCHI, 2011).

A ideia do desenvolvimento sustentável, neste caso, centra-se nas dimensões do Triple Bottom Line (ELKINGTON, 1997), ou seja, o ambiental, social e econômico. Sendo assim, quando se refere a gestão ambiental, a abrangência deve ser as dimensões da Triple Bottom Line. Esta ideia está associada ao discurso de Yamaguchi (2011, p. 60), onde o desenvolvimento sustentável "[...] busca melhorias nas condições sociais e econômicas sem que haja o comprometimento das condições ambientais, implica na melhoria das condições sociais, mas sempre garantindo a sustentabilidade ambiental."

A gestão ambiental consiste em um conjunto de atividades administrativas e operacionais, a saber, controle, direção, planejamento, alocação de recursos e demais atividades com efeitos positivos ao meio ambiente (BARBIERI, 2007). Esta gestão é um conjunto de rotinas e procedimentos utilizadas na administração das atividades relacionadas a questão 
ambiental (RIBEIRO, 2005).

A gestão ambiental, em um conceito amplo, é entendida como um sistema que inclui a estrutura organizacional (atividades de planejamento, responsabilidades, práticas, procedimentos, processos e recursos) para desenvolver, implementar, atingir, analisar e manter a política ambiental (TINOCO; KRAEMER, 2011).

O principal objetivo da gestão ambiental é proporcionar benefícios à empresa, com o propósito de diminuir os gastos da degradação oriundos do sistema produtivo (FERREIRA, 2003). Além disso, ainda comenta que a organização pode ter outros benefícios com a implantação da gestão ambiental, tais como: a) diminuir a necessidade de tratamento de saúde; b) aumento da produção e de suas vendas; c) não receber multas; d) não indenizar terceiros em decorrência de problemas causados ao meio ambiente; e entre outros.

A gestão ambiental, social e econômica são exequíveis com maior facilidade mediante o auxílio da apuração do desempenho empresarial, além disso, esta ideia tem aderência ao desenvolvimento sustentável. Nota-se um processo em cadeia, onde a mensuração do desempenho empresarial leva a gestão, e esta tem como ação o desenvolvimento sustentável para implementar as melhorias empresariais.

\section{DESEMPENHO AMBIENTAL}

As corporações, em especial, nos países em desenvolvimento enfrentam de forma crescente novos desafios, devido as regras das normas éticas, trabalhistas e ambientais no processo organizacional (TUPY, 2008). Além disso, a conquista da reputação socioambiental das organizações é alicerçada na transmissão de transparência e confiabilidade nas ações. Neste contexto, as organizações podem analisar o desempenho ambiental e social, em conjunto com o econômico.

O desempenho ambiental procura obter resultados mensuráveis do gerenciamento de aspectos ambientais das atividades, produtos e serviços de uma organização (ALVES, 2012). Desse modo, este autor ainda enfatiza que é o resultado de informações quantificáveis e mensuráveis dos aspectos ambientais, que são relacionadas à prevenção, conservação e a recuperação do meio ambiente ou de um dano causado a partir do processo produtivo.

O desempenho ambiental está estreitamente relacionado com o desempenho estratégico da empresa, sendo uma ferramenta adequada para selecionar indicadores ambientais para conduzir a organização aos objetivos estratégicos (JOHNSON, 1998). Este autor ainda salienta que esses indicadores selecionados necessitam ser relevantes à organização, simples e compreensíveis.

A mensuração do desempenho ambiental da organização pode ser realizada por meio da Equação 1 (ALVES et al., 2013). 
Desempenho Ambiental $=\frac{\text { Total de investimentos ambientais }}{\text { Tamanho da empresa }}$

Onde, o total de investimentos ambientais refere-se ao indicador do GRI EN30 ou EN31 (total geral de investimentos em gastos e proteção ambiental), e o Tamanho da Empresa, segundo Alves et al. (2013), pode ser utilizado o valor referente a receita total.

\section{DESEMPENHO SOCIAL}

O desempenho social empresarial pode ser entendido como uma empresa de negócios atrelada a princípios relacionados a responsabilidade social, programas sociais, políticas, entre outros (WOOD, 1991; WOOD, 2010). O desempenho social pode ser quantificado por meio da Equação 2, utilizando-se a mesma lógica do desempenho ambiental.

Desempenho Social $=\frac{\text { Total de investimentos sociais }}{\text { Tamanho da empresa }}$

Onde, o total de investimentos sociais refere-se a soma dos gastos em educação, cultura, saúde e saneamento, esporte, treinamentos, entre outros; e o Tamanho da empresa é aderente ao valor da receita total, segundo Alves et al. (2013).

\section{DESEMPENHO ECONÔMICO}

O desempenho econômico empresarial pode ser medido pelo seu lucro com auxílio de um indicador, além disso, também pode ser medido pelo valor que a empresa possui no mercado financeiro, pelo valor de suas ações ou pela sua taxa de crescimento (ROLDAN et al., 2012). O nível deste desempenho pode ser mensurado por meio de indicadores contábeis, como Return on Assets (ROA), Return on Equity (ROE), Return on Ivestments (ROI), Return on Sales (ROS), Return on Market (ROM), Lucro Operacional sobre o Ativo Total (LOAT), e Earnings Before Interest, Taxes, Depreciation and Amortization (EBITDA). Na sequência apresenta-se o conceito e a forma de mensuração destes indicadores.

O ROA é uma "[...] taxa de retorno gerado pelas aplicações realizadas por uma empresa em seus ativos. Indica o retorno gerado por cada \$1,00 investido pela empresa" (ASSAF NETO, 2008, p. 229). Este autor destaca que a apuração do ROA pode ocorrer por meio da Equação 3. 
ROA $=\frac{\text { Lucro Operacional }}{\text { Ativo Total Médio }}$

Os benefícios proporcionados pelo ROA para auxiliar os gestores, segundo Wernke (2008) centram-se na avaliação da margem de lucro, a mensuração da eficiência dos ativos permanentes, a avaliação do capital de giro, a gestão dos custos e despesas, entre outras.

O ROE "[...] evidencia o retorno do capital próprio (PL) aplicado na empresa" (WERNKE, 2008, p. 267), sendo apurado conforme Equação 4.

ROE $=\frac{\text { Lucro Líquido }}{\text { Patrimônio Líquido Médio }}$

A análise do ROE consiste em cada $\$ 1,00$ de recursos próprios que a organização possui investido o quanto que os acionistas ganham de retorno (WERNKE, 2008).

O ROI consiste em "[...] uma alternativa ao uso do ROA para avaliar o retorno produzido pelo total dos recursos aplicados por acionistas e credores nos negócios" (ASSAF NETO, 2008, p. 284), e a Equação 5 é utilizada na sua apuração.

$\mathrm{ROI}=\frac{\text { Lucro operacional }}{\text { Investimento Médio }}$

Onde, o lucro operacional é o valor antes do imposto de renda e da contribuição social, e o valor do investimento médio apura-se com base na diferença entre o ativo total e o passivo de funcionamento (aqueles investidos efetivos na organização, por exemplo, salários, fornecedores, impostos, entre outros).

O ROS é definido como o lucro dividido pelas receitas (ROBINSON; MCDOUGALL, 2001). A apuração realiza-se por meio da Equação 6.

ROS $=\frac{\text { Lucro Líquido }}{\text { Receita Líquida }}$

O ROM, ou seja, o Q de Tobin, representa a razão entre o valor de mercado de determinado ativo e seu custo de reposição (NAKAO et al., 2007). A Equação 7 apresenta a forma de cálculo. 
$R O M=\frac{V M A+V M D}{V R A}$

Onde, o VMA representa o valor de mercado das ações (ou capital próprio da corporação); o VMD compreende o valor de mercado das dívidas (ou capital de terceiros empregados); e o VRA é o valor de reposição dos ativos corporação.

O LOAT é definido como o retorno do lucro operacional sobre o ativo total e apura-se com base na Equação 8 (SILVEIRA et al., 2004).

LOAT $=\frac{\text { Lucro Operacional }}{\text { Ativo Total }}$

O EBITDA "[...] equivale ao conceito restrito de fluxo de caixa operacional da empresa apurado antes do cálculo do imposto de renda" (ASSAF NETO, 2008, p. 207). O valor do EBITDA pode ser apurado, segundo Frezatti e Aguiar (2007, p. 13), com base na Equação 9.

EBITDA = Lucro Líquido + Depreciação + Despesas Financeiras + IRPJ e CS

O EBITDA consiste na avaliação de quanto os ativos operacionais geram de retorno em valores monetários, sendo assim, quanto maior o EBITDA, maior é a capacidade da geração de caixa da organização (ASSAF NETO, 2008). Após apresentar os indicadores de desempenho ambiental, social e econômico na sequencia apresenta-se os resultados de estudos precedentes sobre o tema em tela.

RESULTADOS DE ESTUDOS PRECEDENTES SOBRE DESEMPENHOS AMBIENTAL, SOCIAL E

ECONÔMICO

O detalhamento dos resultados de estudos precedentes correlatos sobre a influência entre os desempenho ambiental, social e econômico é essencial para auxiliar na análise e discussão dos resultados desta pesquisa. Estes estudos precedentes foram recuperados do buscador Google Scholar utilizando-se as palavras chave "correlação" "desempenho ambiental", "desempenho social", "desempenho econômico". Os estudos apresentados no Quadro 1 não exaurem a literatura sobre o assunto, mas em função da aderência ao tema tratado nesta pesquisa selecionou-se estes para uma breve descrição. 
Quadro 1 - Resultados de estudos precedentes

\begin{tabular}{|c|c|c|c|c|}
\hline Autor e ano & Ambiental & Social & Econômica & Resultado \\
\hline Alves et al. (2013) & $\begin{array}{l}\text { Investimentos } \\
\text { ambientais }\end{array}$ & - & $\begin{array}{l}\text { ROA, ROE, ROS e } \\
\text { ROM (Q de } \\
\text { Tobin) }\end{array}$ & $\begin{array}{l}\text { Há correlação significativa } \\
\text { apenas entre ROA e EN30. }\end{array}$ \\
\hline $\begin{array}{l}\text { Parente, luca e } \\
\text { Rmcy (2016) }\end{array}$ & $\begin{array}{l}\text { Investimentos } \\
\text { ambientais }\end{array}$ & - & ROA e ROE & $\begin{array}{l}\text { Não há correlações } \\
\text { significativas. }\end{array}$ \\
\hline $\begin{array}{l}\text { Alberton e Costa } \\
\text { Júnior (2007) }\end{array}$ & $\begin{array}{l}\text { Investimentos } \\
\text { ambientais }\end{array}$ & - & ROA, ROE e ROS & $\begin{array}{l}\text { Há correlação significativa } \\
\text { entre o ambiental e o ROA. }\end{array}$ \\
\hline $\begin{array}{l}\text { Moneva e Cuellar } \\
\text { (2009) }\end{array}$ & - & $\begin{array}{l}\text { Aggregate } \\
\text { score of CSP } \\
\text { developed by } \\
\text { MJRA }\end{array}$ & $\begin{array}{l}\text { Market returns, } \\
\text { ROA, ROE, }\end{array}$ & $\begin{array}{l}\text { O CSP não teve correlação } \\
\text { significativa em relação ao } \\
\text { ROA e ROE, apenas em } \\
\text { função do Market returns. }\end{array}$ \\
\hline Roldan et al. (2012) & $\begin{array}{l}\text { Investimentos } \\
\text { ambientais }\end{array}$ & - & $\begin{array}{l}\text { ROE, receita } \\
\text { líquida, resultado } \\
\text { operacional }\end{array}$ & $\begin{array}{l}\text { Não houve correlação } \\
\text { significativa entre ROE e } \\
\text { ambiental, mas entre receita } \\
\text { líquida e operacional houve. }\end{array}$ \\
\hline Bufoni (2009) & $\begin{array}{l}\text { Investimentos } \\
\text { ambientais }\end{array}$ & - & ROE & $\begin{array}{l}\text { Não houve correlação } \\
\text { significativa. }\end{array}$ \\
\hline $\begin{array}{l}\text { Wang, Dou e Jia } \\
\text { (2016) }\end{array}$ & $\begin{array}{l}\text { Investimentos } \\
\text { ambientais }\end{array}$ & - & $\begin{array}{l}\text { ROA, ROS e Q de } \\
\text { Tobin }\end{array}$ & $\begin{array}{l}\text { Existem correlações } \\
\text { significativas. }\end{array}$ \\
\hline $\begin{array}{l}\text { Allouche e Laroche } \\
\text { (2005) }\end{array}$ & - & $\begin{array}{l}\text { Investimentos } \\
\text { Sociais }\end{array}$ & $\begin{array}{l}\text { ROA, ROS, ROE e } \\
\text { Q de Tobin }\end{array}$ & $\begin{array}{l}\text { Existem correlações } \\
\text { significativas. }\end{array}$ \\
\hline $\begin{array}{l}\text { Orlitzky, Schmidt e } \\
\text { Rynes (2003) }\end{array}$ & $\begin{array}{l}\text { Investimentos } \\
\text { ambientais }\end{array}$ & $\begin{array}{l}\text { Investimentos } \\
\text { Sociais }\end{array}$ & ROA, ROS e ROE & $\begin{array}{l}\text { Há correlação significativa do } \\
\text { social e ambiental com o } \\
\text { econômico. }\end{array}$ \\
\hline Soana (2011) & - & Ethical rating & $\begin{array}{l}\text { Market and } \\
\text { accounting ratios }\end{array}$ & $\begin{array}{l}\text { Não houve correlação } \\
\text { significativa. }\end{array}$ \\
\hline $\begin{array}{l}\text { Holanda et al. } \\
\text { (2011) }\end{array}$ & $\begin{array}{l}\text { Investimentos } \\
\text { ambientais }\end{array}$ & $\begin{array}{l}\text { Investimentos } \\
\text { Sociais }\end{array}$ & ROA & $\begin{array}{l}\text { Não houve correlação } \\
\text { significativa. }\end{array}$ \\
\hline $\begin{array}{l}\text { Reis, Moreira e } \\
\text { França (2013) }\end{array}$ & $\begin{array}{l}\text { Investimentos } \\
\text { ambientais }\end{array}$ & - & ROA e ROE & $\begin{array}{l}\text { Há correlação significativa } \\
\text { entre o ambiental e do ROA e } \\
\text { ROE. }\end{array}$ \\
\hline Qi et al. (2014) & $\begin{array}{l}\text { Investimentos } \\
\text { ambientais }\end{array}$ & - & $\mathrm{ROA}$ & $\begin{array}{l}\text { Há correlação significativa do } \\
\text { ambiental e do ROA. }\end{array}$ \\
\hline
\end{tabular}

Fonte: Elaborado pelos autores.

A análise destes estudos sobre a correlação entre os desempenhos ambiental, social e econômico revelam resultados conflitantes (SOANA, 2011). Neste sentido, Moneva e Cuellar (2009) justificam estes resultados estão em função da diversidade de métodos de pesquisas utilizados e a ausência de medidas consistentes do desempenho ambiental e social. Além disso, Orlitzky, Schmidt e Rynes (2003) sugerem que a relação entre o desempenho social e ambiental e o econômico é versátil, o que torna difícil emitir quaisquer conclusões generalizadas. 


\section{PROCEDIMENTOS METODOLÓGICOS}

\section{CLASSIFICAÇÃO DA PESQUISA}

A pesquisa quanto a abordagem é quantitativa, pois possui a intenção de garantir a precisão dos resultados, evitando distorções nas análises e interpretações, além disso, é caracterizada pelas quantificações na coleta de informações e do tratamento de técnicas estatísticas, tais como: percentual, média, desvio-padrão, correlação e regressão (RICHARDSON, 2010). A abordagem quantitativa adere-se a esta pesquisa, pois se utiliza de métodos estatísticos, tais como a correlação de Pearson, Teste de Levene, Teste $t$ de Student, com o auxílio do Software IBM SPSS Statistics 23.

Os procedimentos técnicos vinculam-se a documental, pois os dados coletados são provenientes de documentos que não receberam tratamento analítico (GIL, 2012). A pesquisa quanto ao objetivo é descritiva, que tem como principal finalidade descrever as características de determinada população ou estabelecimento de relações entre variáveis (GIL, 2012).

\section{UNIDADE DE ANÁLISE}

A unidade de análise compreende 18 corporações com maior faturamento cadastradas na carteira ISE da BM\&FBovespa, no ano de 2016 (QUADRO 2).

Quadro 2 - Características das corporações

\begin{tabular}{|c|c|c|c|}
\hline Empresa & Setor & Atividade & Sede \\
\hline $\begin{array}{l}\text { BANCO DO } \\
\text { BRASIL }\end{array}$ & Financeiro & Banco Múltiplo & Brasília \\
\hline $\begin{array}{l}\text { BANCO } \\
\text { BRADESCO }\end{array}$ & Financeiro & Prática de Operações Bancárias em Geral. & São Paulo \\
\hline BRASKEM & Combustível & Prod. de Prod. Quím. E Petroquímicos Básicos. & São Paulo \\
\hline BRF & Alimentício & Produção de Alimentos Processados/Carnes & São Paulo \\
\hline CCR & Transportes & $\begin{array}{l}\text { Prest. de Serv. Púb. Por Meio de Conc. Rod, Metroviária e } \\
\text { Aeroportuária }\end{array}$ & São Paulo \\
\hline CEMIG & $\begin{array}{l}\text { Energia } \\
\text { elétrica }\end{array}$ & $\begin{array}{l}\text { Planejar. Projetar. Construir. Operar e Explorar Sistemas de } \\
\text { Distribuição }\end{array}$ & $\begin{array}{l}\text { Minas } \\
\text { Gerais }\end{array}$ \\
\hline CIELO & Financeiro & $\begin{array}{l}\text { Empresa Prestadora de Serviços de Aquirencia e Meios de } \\
\text { Pagamento. }\end{array}$ & São Paulo \\
\hline COPEL & $\begin{array}{l}\text { Energia } \\
\text { elétrica }\end{array}$ & $\begin{array}{l}\text { Geração. Transmissão. Comercialização e Distribuição de } \\
\text { Energia Elétrica }\end{array}$ & Paraná \\
\hline CPFL & $\begin{array}{l}\text { Energia } \\
\text { elétrica }\end{array}$ & $\begin{array}{l}\text { Geração. Transmissão. Comercialização e Distribuição de } \\
\text { Energia Elétrica }\end{array}$ & Campinas \\
\hline ELETROPAULO & $\begin{array}{l}\text { Energia } \\
\text { elétrica }\end{array}$ & Distribuição de Energia Elétrica & São Paulo \\
\hline EMBRAER & Transportes & Produção de Aeronaves & São Paulo \\
\hline FIBRIA & Extração & Extração e produção de Materiais Básicos, madeira, Papel e & São Paulo \\
\hline
\end{tabular}




\begin{tabular}{|c|c|c|c|}
\hline & & Celulose & \\
\hline $\begin{array}{l}\text { ITAU } \\
\text { UNIBANCO }\end{array}$ & Financeiro & Atividade Bancária & São Paulo \\
\hline $\begin{array}{l}\text { BANCO } \\
\text { SANTANDER }\end{array}$ & Financeiro & Atividade Bancária. & São Paulo \\
\hline SUL AMERICA & Seguros & $\begin{array}{l}\text { Venda de Seguros. Prev. Comp.. Adm. de Recursos. Cap. e } \\
\text { Assistência à Saúde. }\end{array}$ & $\begin{array}{l}\text { Rio de } \\
\text { Janeiro }\end{array}$ \\
\hline $\begin{array}{l}\text { TELEFONICA } \\
\text { BRASIL }\end{array}$ & $\begin{array}{l}\text { Telecomunica } \\
\text { ções }\end{array}$ & Prestação de Serviços Públicos de Telecomunicações & São Paulo \\
\hline TIM & $\begin{array}{l}\text { Telecomunica } \\
\text { ções }\end{array}$ & Serviços de telecomunicações & $\begin{array}{l}\text { Rio de } \\
\text { Janeiro }\end{array}$ \\
\hline WEG & Indústria & Sociedade de Participação Não Operacional (holding) & $\begin{array}{l}\text { Santa } \\
\text { Catarina }\end{array}$ \\
\hline
\end{tabular}

Fonte: Elaborado com base em BM\&FBovespa (2017a).

A ISE é uma ferramenta que analisa e compara a performance sob aspectos da sustentabilidade das empresas baseando-se na eficiência econômica, equilíbrio ambiental, governança corporativa e justiça social (BM\&FBOVESPA, 2017a). Além disso, as corporações que fazem parte da ISE são avaliadas pelo comprometimento com a sustentabilidade, por meio da natureza dos produtos, transparência e prestação de contas, compromisso com o desenvolvimento sustentável e o desempenho nas dimensões econômica, ambiental e social.

\section{COLETA E ANÁLISE DOS DADOS}

A coleta das informações ocorreu por intermédia da pesquisa documental no site da BM\&FBovespa (2017b). Os relatórios coletados de cada corporação correspondem as demonstrações financeiras e com base nestes, coletou-se o Ativo Total, Receita Total, Patrimônio Líquido, Lucro Líquido, Lucro Operacional Próprio, Lucro Operacional, Lucro Antes IRPJ e CS, Capital de Terceiros e Valor de Mercado, referente ao exercício social de 2016. Estas informações foram tabuladas, com auxílio de Softwares da Microsoft Office de edição de texto e planilhas eletrônicas, para a realização dos cálculos e elaboração de tabelas com a finalidade de compilar os dados e analisar a relação dos desempenhos econômicos, sociais e ambientais.

As análises ocorreram por meio da correlação de Pearson, Teste $t$ de student, Teste de Levene e pelo coeficiente de variação. Sendo assim, o coeficiente de correlação de Pearson consiste em uma medida relativa utilizada para comparar o grau de concentração em torno da média de séries distintas (OLIVEIRA, 2007). O coeficiente de correlação de Pearson é uma medida de associação linear entre variáveis quantitativas e seu resultado centra-se de -1 a +1 (OLIVEIRA, 2007).

A variância entre os grupos do desempenho ambiental e social foi apurada pelo Teste $t$ de student e controlado pelo Teste de Levene. O Teste Levene verifica se as variâncias de diferentes grupos são iguais (FIELD, 2009). O Teste Levene é significativo com resultado de $p \leq$ 0.05 , neste caso, a hipótese nula é rejeitada e as variancias podem ser consideradas distintas. 
O Teste $t$ de Student é utilizado na avaliação da hipótese se as variancias das médias são iguais ou diferentes, sendo assim, se o $p<0,05$ pode-se sugerir que não haja diferenças entre as médias, ou seja, aceita-se a hipótese nula (FIELD, 2009).

O coeficiente de variação é uma medida de precisão, pois se a variação for menor que 10\% (baixo), ou seja, alta precisão; e de 10 a 20\%(moderada), de 20 a 30\% (alta), acima de 30\% (muito alta), ou seja, baixa precissão (PIMENTEL GOMES, 2000).

\section{RESULTADOS E ANÁLISES}

DESEMPENHO AMBIENTAL E SOCIAL

A apuração do desempenho ambiental (EQUAÇÃO 1) e social (EQUAÇÃO 2) apontam uma média de 0,263 e 0,238, respectivamente, de investimento na área ambiental e social em relação a receita líquida (TABELA 1).

Tabela 1 - Desempenho ambiental e social

\begin{tabular}{|c|c|c|}
\hline Empresas & Desempenho ambiental & Desempenho social \\
\hline BANCO DO BRASIL S.A & 0,215 & 0,067 \\
\hline BANCO BRADESCO S.A & 0,016 & 0,488 \\
\hline BRASKEM S.A & 0,379 & 0,058 \\
\hline BRF S.A & 0,834 & 0,055 \\
\hline CCR S.A & 0,214 & 0,544 \\
\hline CEMIG S.A & 0,225 & 0,293 \\
\hline CIELO S.A & 0,012 & 0,176 \\
\hline COPEL S.A & 0,023 & 0,135 \\
\hline CPFL S.A & 0,430 & 0,511 \\
\hline ELETROPAULO S.A & 0,373 & 0,624 \\
\hline EMBRAER S.A & 0,035 & 0,058 \\
\hline FIBRIA S.A & 1,581 & 0,429 \\
\hline ITAU UNIBANCO S.A & 0,018 & 0,320 \\
\hline BANCO SANTANDER S.A & 0,035 & 0,169 \\
\hline SUL AMERICA S.A & 0,041 & 0,042 \\
\hline TELEFONICA BRASIL S.A & 0,202 & 0,099 \\
\hline TIM S.A & 0,057 & 0,128 \\
\hline WEG S.A & 0,061 & 0,098 \\
\hline Média aritmética & 0,263 & 0,238 \\
\hline
\end{tabular}

Fonte: Elaborado pelos autores.

$\mathrm{Na}$ área ambiental o maior desempenho ocorreu nas empresas dos setores de combustível (BRASKEM), alimentício (BRF) e extração de recursos naturais (FIBRIA). Este comportamento pode ser explicado em função de estarem entre aqueles com maior potencial 
de poluição, por este fato pode haver maior investimento ambiental, pela pressão exercida de políticas e normas governamentais e pela sociedade, entre outros, fato que também é defendido por Marta et al. (2011).

$\mathrm{Na}$ área social o melhor desempenho está relacionado ao setor de transportes (CCR) e energia elétrica (CPFL e ELETROPAULO). Os setores de transporte e de energia elétrica estão sendo alvos de investimentos, no Brasil, conforme Máximo (2017). O coeficiente de variação revela que o desempenho ambiental $(1,482)$ e social $(0,827)$, possuem uma alta dispersão, ou seja, baixa precisão, o que fortalece a ideia de não haver um padrão de investimento na área ambiental e social entre as diferentes corporações.

\section{DESEMPENHO ECONÔMICO}

A análise do desempenho econômico revela que a Braskem e a BRF possuem prejuízo (TABELA 2), o que inviabiliza a geração de lucro, mas nota-se que estas organizações realizam investimentos ambientais e sociais (TABELA 1 ).

Tabela 2 - Desempenhos econômicos

\begin{tabular}{l|l|l|l|l}
\hline Empresas & ROA & ROE & ROI & ROS \\
\hline BANCO DO BRASIL S.A & 0,79 & 9,61 & 12,09 & 3,89 \\
\hline BANCO BRADESCO S.A & 2,68 & 14,30 & 30,25 & 8,05 \\
\hline BRASKEM S.A & $-0,27$ & $-42,38$ & $-8,14$ & $-1,32$ \\
\hline BRF S.A & $-0,74$ & $-3,01$ & $-2,60$ & $-0,94$ \\
\hline CCR S.A & 10,05 & 39,51 & 59,52 & 16,38 \\
\hline CEMIG S.A & 2,60 & 13,39 & 17,07 & 1,43 \\
\hline CIELO S.A & 19,71 & 32,42 & 46,66 & 30,89 \\
\hline COPEL S.A & 4,86 & 6,33 & 9,75 & 7,32 \\
\hline CPFL S.A & 3,27 & 8,47 & 13,31 & 2,86 \\
\hline ELETROPAULO S.A & 0,11 & 0,78 & 0,57 & 0,10 \\
\hline EMBRAER S.A & 1,46 & 4,56 & 4,33 & 2,73 \\
\hline FIBRIA S.A & 8,84 & 4,83 & 8,84 & 17,30 \\
\hline ITAU UNIBANCO S.A & 2,82 & 17,49 & 28,33 & 8,05 \\
\hline BANCO SANTANDER S.A & 0,36 & 2,12 & 4,65 & 3,53 \\
\hline SUL AMERICA S.A & 5,23 & 13,79 & 22,61 & 4,14 \\
\hline TELEFONICA BRASIL S.A & 5,03 & 5,90 & 7,42 & 9,61 \\
\hline TIM S.A & 2,92 & 4,37 & 5,90 & 3,31 \\
\hline WEG S.A & 9,47 & 18,32 & 20,78 & 10,31 \\
\hline Fonte: ElabOrado PelOS & & & \\
\hline
\end{tabular}

Fonte: Elaborado pelos autores.

As corporações com melhor desempenho econômico centram-se no setor de serviços financeiros, por exemplo, a CIELO, ITAU Unibanco, SUL América e o Bradesco. Este resultado corrobora com a informação de Pinheiro (2018) quando relata que "[...] Itaú lucra R\$ 24,9 bilhões e pagará 'superdividendo' a acionistas". Salomão (2017) reforça que entre os maiores 
lucros corporativos encontra-se as instituições financeiras.

\section{ANÁLISE DE VARIÂNCIA E CORRELAÇÃO}

A análise de variância entre o desempenho ambiental e social revela um Levene $F$ $(1,296)=0,263$, onde $p>0,05$. Este resultado sugere que não há diferenças significativas entre as variâncias dos desempenhos. $O$ teste $t$ das amostras independentes revela um $t$ de Student $(0,246)=0,807$, onde $p>0,05$, neste caso, o desempenho ambiental e social são iguais em média. Estes resultados sugerem que a média do desempenho ambiental $(0,263)$ é igual ao desempenho social $(0,238)$.

A correlação de Pearson revela que não houve correlação significativa entre o desempenho ambiental (investimentos ambientais), social (investimentos sociais) e econômico (ROA, ROE, ROI, ROS) (TABELA 3). Este resultado corrobora com os achados de Parente, luca e Rmcy (2016), Bufoni (2009), Moneva e Cuellar (2009), Roldan et al. (2012) e Soana (2011), pois também não encontraram correlações significativas entre estes desempenhos. Entretanto, os resultados de Wang, Dou e Jia (2016), Allouche e Laroche (2005), Alberton e Costa Júnior (2007) e Alves et al. (2013) sugerem uma correlação significativa entre este desempenhos. Neste sentido, percebe-se que não existe um consenso de que os desempenhos ambientais e sociais influenciam de forma significativa no desempenho econômico, o que corrobora com Orlitzky, Schmidt e Rynes (2003) e Moneva e Cuellar (2009) quando sugerem que a correlação entre os desempenhos pode ser positiva, negativa e não significativa (neutra). 
Tabela 3 - Resultados da Correlação do Pearson

\begin{tabular}{|c|c|c|c|c|c|c|c|c|c|c|c|c|c|c|c|}
\hline & 1 & 2 & 3 & 4 & 5 & 6 & 7 & 8 & 9 & 10 & 11 & 12 & 13 & 14 & $\begin{array}{l}1 \\
5\end{array}$ \\
\hline (1) $\mathrm{ROA}$ & 1 & & & & & & & & & & & & & & \\
\hline (2) ROE & $\begin{array}{l}, 644 \\
* *\end{array}$ & 1 & & & & & & & & & & & & & \\
\hline (3) $\mathrm{ROI}$ & $\begin{array}{l}, 715 \\
* *\end{array}$ & $\begin{array}{l}859 \\
* *\end{array}$ & 1 & & & & & & & & & & & & \\
\hline (4) ROS & $\begin{array}{l}, 948 \\
* *\end{array}$ & $\begin{array}{l}, 643 \\
* *\end{array}$ & $\begin{array}{l}721 \\
* *\end{array}$ & 1 & & & & & & & & & & & \\
\hline $\begin{array}{l}\text { (5) Desempenho } \\
\text { ambiental }\end{array}$ & $\begin{array}{l}- \\
0,02 \\
4\end{array}$ & $\begin{array}{l}- \\
0,26 \\
1\end{array}$ & $\begin{array}{l}- \\
0,30 \\
1\end{array}$ & $\begin{array}{l}0,0 \\
43\end{array}$ & 1 & & & & & & & & & & \\
\hline $\begin{array}{l}\text { (6) Desempenho } \\
\text { social }\end{array}$ & $\begin{array}{l}0,08 \\
1\end{array}$ & $\begin{array}{l}0,31 \\
7\end{array}$ & $\begin{array}{l}0,35 \\
3\end{array}$ & $\begin{array}{l}0,1 \\
58\end{array}$ & $\begin{array}{l}0,2 \\
46\end{array}$ & 1 & & & & & & & & & \\
\hline (7) Ativo Total & $\begin{array}{l}- \\
0,28 \\
5 \\
\end{array}$ & \begin{tabular}{|l|}
- \\
0,03 \\
1 \\
\end{tabular} & \begin{tabular}{|l|}
- \\
0,06 \\
9 \\
\end{tabular} & $\begin{array}{l}- \\
0,1 \\
19\end{array}$ & $\begin{array}{l}- \\
0,2 \\
27\end{array}$ & $\begin{array}{l}- \\
0,0 \\
45 \\
\end{array}$ & 1 & & & & & & & & \\
\hline (8) Receita Total & $\begin{array}{l}- \\
0,35 \\
6\end{array}$ & \begin{tabular}{|l|}
- \\
0,00 \\
2
\end{tabular} & 0,04 & $\begin{array}{l}- \\
0,1 \\
44\end{array}$ & $\begin{array}{l}- \\
0,2 \\
58\end{array}$ & $\begin{array}{l}0,0 \\
12\end{array}$ & $\begin{array}{l}, 740 \\
* *\end{array}$ & 1 & & & & & & & \\
\hline $\begin{array}{l}\text { (9) Patrimônio } \\
\text { Líquido }\end{array}$ & $\begin{array}{l}- \\
0,25 \\
2\end{array}$ & \begin{tabular}{|l|} 
\\
0,01 \\
6
\end{tabular} & \begin{tabular}{|l|} 
\\
0,07 \\
3
\end{tabular} & $\begin{array}{l}- \\
0,0 \\
64\end{array}$ & $\begin{array}{l}- \\
0,1 \\
93\end{array}$ & \begin{tabular}{|l|}
- \\
0,0 \\
4
\end{tabular} & $\begin{array}{l}, 981 \\
* *\end{array}$ & $\begin{array}{l}, 742 \\
* *\end{array}$ & 1 & & & & & & \\
\hline (10) Lucro Líquido & $\begin{array}{l}- \\
0,06 \\
2\end{array}$ & $\begin{array}{l}0,25 \\
4\end{array}$ & $\begin{array}{l}0,31 \\
4\end{array}$ & $\begin{array}{l}0,1 \\
45\end{array}$ & $\begin{array}{l}- \\
0,2 \\
83\end{array}$ & $\begin{array}{l}0,1 \\
67\end{array}$ & $\begin{array}{l}, 505 \\
*\end{array}$ & $\begin{array}{l}, 889 \\
* *\end{array}$ & $\begin{array}{l}, 557 \\
*\end{array}$ & 1 & & & & & \\
\hline $\begin{array}{l}\text { (11) Lucro } \\
\text { Operacional Próprio }\end{array}$ & $\begin{array}{l}- \\
0,16 \\
6 \\
\end{array}$ & $\begin{array}{l}0,11 \\
2 \\
\end{array}$ & $\begin{array}{l}0,24 \\
7 \\
\end{array}$ & $\begin{array}{l}0,0 \\
45\end{array}$ & $\begin{array}{l}- \\
0,2 \\
8\end{array}$ & $\begin{array}{l}0,1 \\
97\end{array}$ & $\begin{array}{l}, 550 \\
*\end{array}$ & $\begin{array}{l}, 887 \\
* * \\
\end{array}$ & $\begin{array}{l}, 594 \\
* * \\
\end{array}$ & $\begin{array}{l}966 \\
* * \\
\end{array}$ & 1 & & & & \\
\hline $\begin{array}{l}\text { (12) Lucro } \\
\text { Operacional }\end{array}$ & $\begin{array}{l}- \\
0,09 \\
7\end{array}$ & $\begin{array}{l}0,21 \\
1 \\
\end{array}$ & $\begin{array}{l}0,29 \\
5 \\
\end{array}$ & $\begin{array}{l}0,1 \\
15\end{array}$ & $\begin{array}{l}- \\
0,2 \\
78\end{array}$ & $\begin{array}{l}0,2 \\
13\end{array}$ & $\begin{array}{l}, 559 \\
*\end{array}$ & $\begin{array}{l}, 879 \\
* * \\
\end{array}$ & $\begin{array}{l}, 607 \\
* * \\
\end{array}$ & $\begin{array}{l}, 982 \\
* *\end{array}$ & $\begin{array}{l}988 \\
* *\end{array}$ & 1 & & & \\
\hline $\begin{array}{l}\text { (13) Lucro Antes do } \\
\text { IR }\end{array}$ & \begin{tabular}{|l|}
- \\
0,27 \\
8 \\
\end{tabular} & \begin{tabular}{|l|}
- \\
0,02 \\
2 \\
\end{tabular} & \begin{tabular}{|l}
0,06 \\
1 \\
\end{tabular} & \begin{tabular}{|l|}
- \\
0,0 \\
67 \\
\end{tabular} & \begin{tabular}{|l|} 
\\
0,3 \\
19 \\
\end{tabular} & $\begin{array}{l}0,0 \\
03\end{array}$ & 0,45 & $\begin{array}{l}, 761 \\
* * \\
\end{array}$ & $\begin{array}{l}, 501 \\
* \\
\end{array}$ & $\begin{array}{l}, 814 \\
* * \\
\end{array}$ & $\begin{array}{l}, 848 \\
* * \\
\end{array}$ & $\begin{array}{l}834 \\
* * \\
\end{array}$ & 1 & & \\
\hline $\begin{array}{l}\text { (14) Capital de } \\
\text { Terceiros }\end{array}$ & $\begin{array}{l}- \\
0,28 \\
6\end{array}$ & \begin{tabular}{|l|}
- \\
0,03 \\
3
\end{tabular} & \begin{tabular}{|l|}
- \\
0,07 \\
3
\end{tabular} & $\begin{array}{l}- \\
0,1 \\
23\end{array}$ & $\begin{array}{l}- \\
0,2 \\
24\end{array}$ & \begin{tabular}{|l|}
- \\
0,0 \\
49
\end{tabular} & $\begin{array}{l}1,00 \\
0 * *\end{array}$ & $\begin{array}{l}, 736 \\
* *\end{array}$ & $\begin{array}{l}978 \\
* *\end{array}$ & $\begin{array}{l}, 494 \\
*\end{array}$ & $\begin{array}{l}, 538 \\
*\end{array}$ & $\begin{array}{l}, 547 \\
*\end{array}$ & $\begin{array}{l}0,43 \\
8\end{array}$ & 1 & \\
\hline $\begin{array}{l}\text { (15) Valor de } \\
\text { Mercado }\end{array}$ & 0,02 & $\begin{array}{l}0,22 \\
6\end{array}$ & $\begin{array}{l}0,35 \\
1\end{array}$ & $\begin{array}{l}0,2 \\
04\end{array}$ & $\begin{array}{l}- \\
0,1 \\
51\end{array}$ & $\begin{array}{l}0,1 \\
42\end{array}$ & $\begin{array}{l}0,24 \\
9\end{array}$ & $\begin{array}{l}, 717 \\
* *\end{array}$ & $\begin{array}{l}0,27 \\
7\end{array}$ & $\begin{array}{l}, 848 \\
* *\end{array}$ & $\begin{array}{l}, 843 \\
* *\end{array}$ & $\begin{array}{l}, 836 \\
* *\end{array}$ & $\begin{array}{l}, 689 \\
* *\end{array}$ & $\begin{array}{l}0,2 \\
39\end{array}$ & 1 \\
\hline
\end{tabular}

Fonte: Do autor, adaptada a partir do software IBM SPSS 23.

Legenda: * A correlação é significativa no nível 0,05 (bilateral).

** A correlação é significativa no nível 0,01 (bilateral).

Os resultados deste estudo agregam evidencias junto a literatura e as organizações que discutem sobre as influencias entre os desempenhos empresariais (ambiental, social e econômico). Neste estudo, a geração de lucro ou prejuízo pelas corporações analisadas não 
pode ser explicado pelos investimentos realizados na área ambiental e social. Sendo assim, as organizações que investem em questões sociais e ambientais devem realiza-los sem terem a pretensão de ganhos econômicos, pelo menos, no curto prazo.

Além disso, cabe destacar que estes resultados devem ser utilizados com cautela, em função de três questões: a) o reflexo do aumento do desempenho econômico pode ocorrer em exercícios sociais posteriores aos investimentos ambientais e sociais realizados na organização, entretanto, neste estudo avalizou-se os desempenhos no mesmo exercício social; b) os resultados não podem ser generalizados, pois servem apenas para a organizações abrangidas pela unidade de análise deste estudo; e c) a utilização de diferentes tipos de indicadores de desempenho ambiental, social e econômico pode gerar resultados distintos daqueles encontrados neste estudo.

\section{CONCLUSÃO}

O escopo central deste estudo objetivou analisar a existência de correlação do desempenho social e ambiental em relação ao desempenho econômico de corporações da carteira ISE da BM\&Fbovespa de 2016. Os resultados apontam que o desempenho ambiental mais elevado ocorreu nas corporações dos setores de combustível, alimentício e de extração de recursos naturais; o desempenho social destacou-se pelas corporações dos setores de transportes e de energia elétrica; e o desempenho econômico pelas corporações dos serviços financeiros.

O desempenho médio ambiental foi de 0,263 e o social de 0,238, sendo assim, o coeficiente de variação sugere ausência de valor padronizado em investimentos nas áreas ambientais e sociais pelas corporações. Além disso, a análise de variância entre as médias do desempenho ambiental e social pelo teste Levene e $t$ de Student apontam que não existe diferença entre a média dos desempenhos ambiental e social. Os resultados também sugerem que o desempenho ambiental e social não influencia no desempenho econômico das corporações.

Conclui-se que a geração de lucro ou prejuízo das corporações da carteira ISE da BM\&FBovespa de 2016 não é afetado pelo montante de investimento realizado no âmbito ambiental e social. Salienta-se que futuras pesquisas podem ser direcionadas a defasagem temporal, pois os reflexos de investimentos ambientais e sociais podem ocorrer ou ser notados pelos diversos stakeholders apenas em períodos futuros. As limitações deste estudo relacionam-se a não utilização da ideia de defasagem temporal entre os investimentos ambientais e sociais em relação à geração do econômico; e os resultados podem ser utilizados apenas para descrever as corporações da unidade de análise deste estudo, não podendo-se generalizar as conclusões. 


\section{REFERÊNCIAS}

ALLOUCHE, J.; LAROCHE, P. A meta-analytical investigation of the relationship between corporate social and financial performance. Revue de gestion des ressources humaines, n. 57, p. 1-29, 2005.

ALBERTON, A.; COSTA JÚNIOR, N. C. A. Meio ambiente e desempenho econômico financeiro: benefícios dos Sistemas de Gestão Ambiental (SGAs) e o impacto da ISO 14001 nas empresas brasileiras. Revista de Administração Contemporânea Eletrônica, v. 1, n. 2, p. 153-171, 2007.

ALVES, J. F. V. et al. Relação entre desempenho econômico e desempenho ambiental de empresas no Brasil e na Espanha. Revista Ambiente Contábil, v. 5, n. 2, p. 151, 2013.

ASSAF NETO, A. Curso de Administração Financeira. São Paulo: Atlas, 2008.

BARBIERI, J. C. Gestão ambiental empresaria: conceitos, modelos e instrumentos. São Paulo. Saraiva, 2007.

BM\&FBovespa. Índice de Sustentabilidade Empresarial (ISE). 2017a. Disponível em: <http://www.bmfbovespa.com.br/pt_br/produtos/indices/indices-de-sustentabilidade/indicede-sustentabilidade-empresarial-ise.htm>. Acesso em: 07 fev. 2018.

BM\&FBovespa. Empresas listadas. 2017b. Disponível em: < http://www.bmfbovespa.com.br /pt_br/produtos/listados-a-vista-e-derivativos/renda-variavel/empresas-listadas.htm $>$. Acesso em: 07 fev. 2018.

BUFONI, A. L. A relação entre performance financeira e ambiental nos países em desenvolvimento: o caso do Brasil. Revista Sociedade, Contabilidade e Gestão, v. 4, n. 2, 2009.

ELKINGTON, J. Cannibals with Forks: the Triple Bottom Line of 21st Century Business. Capstone Publishing. Oxford. 1997.

FERREIRA, A. C. S. Contabilidade Ambiental: Uma informação para o desenvolvimento sustentável. São Paulo, Atlas, 2003.

FIELD, A. Discovering statistics using SPSS. Sage publications, 2009.

FREZATTI, F.; AGUIAR, A. B. EBITDA: possíveis impactos sobre o gerenciamento das empresas. Revista Universo Contábil, v. 3, n. 3, p. 7-24, 2007.

GIL, A. C. Métodos e Técnicas de Pesquisa Social. 6 ed. São Paulo, Atlas, 2012.

HOLANDA, A. P. et al. O desempenho socioambiental nas empresas do setor elétrico brasileiro: uma questão relevante para o desempenho financeiro? Revista de Gestão Social e Ambiental, v. 5, n. 3, p. 53-72, 2011.

JOHNSON, D. E. Applied multivariete methods for data analysts. Duxbury Press, 1998. 
MARTA, F. S. et al. Investimento em controle ambiental no Brasil: fatores determinantes a partir da modelagem estatística. In: ENCONTRO DE ECONOMIA, 39, 2011, Foz do Iguaçu. Anais... Foz do Iguaçu: Anpec, 2011.

MÁXIMO, L. Investimento estrangeiro em infraestrutura sobe $500 \%$ no ano. 2017. Valor econômico. Disponível em: < http://www.valor.com.br/brasil/4983994/investimentoestrangeiro-em-infraestrutura-sobe-500-no-ano>. Acesso em: 07 fev. 2018.

MONEVA, J. M.; CUELLAR, B. The value relevance of financial and non-financial environmental reporting. Environmental and Resource Economics, v. 44, n. 3, p. 441-456, 2009.

NAKAO, Y. et al. Relationship between environmental performance and financial performance: an empirical analysis of Japanese corporations. Business Strategy and the Environment, v. 16, n. 2, p. 106-118, 2007.

OLIVEIRA, Francisco Estevam Martins de. SPSS básico para análise de dados. Rio de Janeiro: Ciência Moderna, 2007.

ORLITZKY, M.; SCHMIDT, F. L.; RYNES, S. L. Corporate social and financial performance: A meta-analysis. Organization studies, v. 24, n. 3, p. 403-441, 2003.

PARENTE, P. H. N.; LUCA, M. M. M.; ROMCY, T. O. Desempenho Ambiental e Desempenho Econômico de Empresas Listadas na BM\&FBovespa. Organizações e Sustentabilidade, v. 3, n. 2, p. 81-115, 2016.

PIMENTEL GOMES, F. Curso de estatística experimental. 14. ed. Piracicaba: Nobel, 2000.

PINHEIRO, V. Itaú lucra R\$24,9 bilhões e pagará 'superdividendo' a acionistas. 2018.

Disponível em: < http://www.valor.com.br/financas/5308437/itau-lucra-r-249-bilhoes-epagara-superdividendo-acionistas>. Acesso em: 08 fev. 2018.

QI, G. Y. et al. Revisiting the relationship between environmental and financial performance in Chinese industry. Journal of environmental management, v. 145, p. 349-356, 2014.

REIS, E. M.; MOREIRA, M. A.; FRANÇA, R. S. Investimento em meio ambiente e o desempenho econômico das empresas aderidas ao Índice Carbono Eficiente-ICO ${ }^{2}$. Revista de educação e pesquisa em contabilidade, v. 7, n. 4, p. 372-386, 2013.

RICHARDSON, R. J. Pesquisa social: métodos e técnicas. 3 Ed., São Paulo: Atlas, 2010.

RIBEIRO, M. S.; MARTINS, E. A informação como instrumento de contribuição da contabilidade para a compatibilização no desenvolvimento econômico e a preservação do meio ambiente. Caderno de Estudos, n. 9, p. 01-13, 1993.

RIBEIRO, M. S. Contabilidade Ambiental. São Paulo, Saraiva, 2005.

ROLDAN, V. P. S. et al. Relação entre a performance ambiental e financeira das empresas de capital aberto listadas na BM\&FBOVESPA. Pensar Contábil, v. 14, n. 54, p. 38-47, 2012. 
ROBINSON, K.; McDOUGALL, P. Entry Barriers and New Venture Performance. Strategic Management Journal, v. 22, p. 659 - 685, 2001.

SALOMÃO, K. Os 20 maiores lucros do 20 trimestre de 2017. 2017. Disponível em: < https://exame.abril.com.br/negocios/os-20-maiores-lucros-do-2o-trimestre-de-2017/>. Acesso em: 08 fev. 2018.

SILVEIRA, A. M. et al. Determinantes da concentração do direito de controle nas companhias abertas brasileiras. In: ENCONTRO BRASILEIRO DE FINANÇAS, v. 4, 2004.

SOUZA, M. A.; RÁSIA, K. A.; JACQUES, F. V. S. Evidenciação de informações ambientais pelas empresas integrantes do índice de Sustentabilidade Empresarial - ISE. Revista Contabilidade e Controladoria, v. 2, n. 1, p. 51-139, 2010.

SOANA, M. G. The relationship between corporate social performance and corporate financial performance in the banking sector. Journal of business ethics, v. 104, n. 1, p. 133, 2011.

TINOCO, J. E. P.; KRAEMER, M. E. P. Contabilidade e Gestão Ambiental. 3. ed. Atlas, 2011.

TUPY, O. Investimentos em meio ambiente, responsabilidade social e desempenho econômico-financeiro de empresas no Brasil. Tékhne-Revista de Estudos Politécnicos, n. 10, p. 73-86, 2008.

YAMAGUCHI, C. K. Contabilidade Ambiental nas Organizações como instrumento de criação do conhecimento. 2011. Tese (doutorado em Engenharia e Gestão do Conhecimento) Universidade Federal de Santa Catarina, Florianópolis, 2011.

WANG, Q.; DOU, J.; JIA, S. A meta-analytic review of corporate social responsibility and corporate financial performance: The moderating effect of contextual factors. Business \& Society, v. 55, n. 8, p. 1083-1121, 2016.

WERNKE, R. Gestão Financeira: Ênfase em Aplicações e Casos Nacionais. Rio de Janeiro: Saraiva, 2008.

WERNKE, R.; LEMBECK, M. Análise de rentabilidade dos segmentos de mercado de empresa distribuidora de mercadorias. Revista Contabilidade \& Finanças, v. 15, n. 35, p. 68-83, 2004.

WCED - World Commission on Environment and Development. Our Common Future. Oxford: Oxford University Press, 1987.

WOOD, D. J. Corporate social performance revisited. Academy of Management Review, v. 16, p. 691-718, 1991.

WOOD, D. J. Measuring corporate social performance: A review. International Journal of Management Reviews, v. 12, n. 1, p. 50-84, 2010. 